\title{
Operative field temperature during transnasal endoscopic cranial base procedures
}

\author{
Tomasz Lyson • Andrzej Sieskiewicz • Andrzej Sobolewski • Robert Rutkowski • \\ Jan Kochanowicz • Grzegorz Turek • Anna Baclawska • Jacek Krajewski • \\ Marek Rogowski • Zenon Mariak
}

Received: 23 November 2012 / Accepted: 24 February 2013 / Published online: 15 March 2013

(C) The Author(s) 2013. This article is published with open access at Springerlink.com

\begin{abstract}
Background Data regarding the safety of endoscopic skull base exploration are very scarce. With this method, fragile vital structures (cranial nerves, the optic complex, brainstem, hypothalamus or cerebral ventricles) are exposed to direct illumination within a closed space. Also, high-speed drills, cauterization and ultrasonic aspiration deliver a significant load of thermal energy. The aim of this study was to record the temperature close to the structures of the skull base and in the intradural space during the procedures performed using extended endoscopic transnasal approaches.

Methods The temperature of the skull base was continuously recorded during six transnasal endoscopic procedures. Implantable copper-constantan thermocouples were inserted:
\end{abstract}

The study was supported by (Polish) National Center of Research and Development (NCBiR), Grant No NN 403211339

T. Lyson $\cdot$ R. Rutkowski $(\bowtie) \cdot$ J. Kochanowicz $\cdot$ G. Turek $\cdot$

Z. Mariak

Department of Neurosurgery, Medical University of Bialystok,

M. Sklodowskiej-Curie 24 A Str.,

15-276 Bialystok, Poland

e-mail: robert.rutkowski@o2.pl

A. Sieskiewicz $\cdot$ M. Rogowski

Department of Otolaryngology, Medical University of Bialystok,

Bialystok, Poland

A. Sobolewski

University of Technology, Bialystok, Poland

A. Baclawska

Student of the Medical University of Bialystok, Bialystok, Poland

J. Krajewski

Department of Anesthesiology, Medical University of Bialystok, Bialystok, Poland one into the esophagus and another through the nostril to reach the operative field at the skull base.

Results At the beginning of the procedure, the temperature of the operative field was on average $36.8^{\circ} \mathrm{C} \pm 0.80^{\circ} \mathrm{C}$, i.e. only $1{ }^{\circ} \mathrm{C}$ higher than the esophageal temperature. Then it grew continuously during the whole procedure, to eventually reach a level of $42-43{ }^{\circ} \mathrm{C}$ at the final stage, whereas the esophageal temperature remained stable. Occasionally, the temperature increased up to $45{ }^{\circ} \mathrm{C}$ during cauterization and ultrasonic aspiration, and even up to $62{ }^{\circ} \mathrm{C}$ during highspeed drilling.

Conclusion Endoscopic skull base surgery is associated with an incessant increase of the temperature of the intraoperative field. The temperature can peak suddenly to levels which can potentially harm neural structures and influence the rate of postoperative complications.

Keywords Endoscopy · Transnasal · Extended approach · Cranial base $\cdot$ Temperature

\section{Introduction}

Using extended transnasal approaches, today the surgeon can explore not only the entire skull base, but also penetrate the cranial cavity, and expose vital and fragile structures like the cranial nerves, the optic complex, brainstem, hypothalamus or cerebral ventricles [1-4]. With the diffusion of these techniques and new endoscopic tools, endoscopic procedures are becoming more and more complex and much longer lasting. A lot of bone drilling is necessary as well as frequent cauterization, and many surgical steps are performed under high magnification. All this involves close range illumination of the structures with a strong beam of light. These maneuvers 
deliver a significant load of thermal energy that (in contrast to "open" brain surgery) cannot dissipate freely to the environment, as the endoscopic surgery is carried out within the confines of surgically enlarged nasal cavity, while several instruments are introduced through the nostrils, "occluding" them.

Is well known that temperature increases above $42{ }^{\circ} \mathrm{C}$ can seriously harm the brain $[5,6]$, but on the other hand it is somewhat surprising that only very scarce and indirect data exist as to thermal effects on the brain during endoscopic transnasal surgery [7, 8]. Kassam et al. have recently reviewed the complications of 800 endoscopic skull base surgeries, and have not mentioned high temperature as a possible source of neural deficits, visual loss and infections which are the most frequent adverse effects of this surgery [1].

In our neurosurgical center, extended transnasal approaches have been performed since 2007 [4, 9], and earlier we studied extensively brain temperature during and after brain surgery $[10,11]$. We decided to position a miniature implantable thermoprobe in close contact with the exposed skull base and cerebral structures in order to measure the temperature during endoscopic transnasal procedures performed via extended approaches.

\section{Methods and materials}

With institutional approval and written informed consent, we measured temperature in the depth of the nasal cavity in six patients who were undergoing endoscopic transnasal surgery for cranial base pathologies. There were two men and four women between the ages of 26 and 58 years. All were operated on under general anesthesia with controlled mild arterial hypotension. Hopkins telescopes II $(18 \mathrm{~cm}, \phi$ $4 \mathrm{~mm}, 0^{\circ}$ and $45^{\circ}$ ), connected to a standard xenon light source (Xenon Nova 175) were used in all instances. Binostril approach and four-hand technique were used in all procedures with no mechanical endoscope holder. Constant suction was maintained during such maneuvers as highspeed drilling of the bone, cauterization and application of ultrasonic aspiration (CUSA). The operative field was poured with lukewarm saline only after each of the above maneuvers and rather sparingly, just to keep the vision clear (see comment in the discussion section). All endoscopic equipment was provided by Karl Storz Endoscope, Germany. The procedures consisted of removal of following pathologies: cholesterol granuloma of the pyramid apex; meningioma of the planum sphenoidale with a suprasellar extension; basal frontal lobe teratoma operated using transplanum approach; giant pituitary adenoma with extension into the third ventricle; sarcoma infiltrating the sphenoid and cavernous sinuses and the upper clivus, and retrochiasmatic craniopharyngioma. No patient had fever nor other detected pathologies.
Temperature measurement

Teflon coated implantable copper-constantan type T thermocouples (Physitemp, USA) were used for all temperature measurements. Intranasal temperature was measured with a $0.2 \mathrm{~mm}$ probe introduced through the right nostril after anterior sphenoidectomy had been performed. The thermocouple was placed as close to the operated structures as possible, and constantly replaced to be illuminated and visible on the screen. When intracranial structures were exposed, the thermocouple was advanced and placed directly on/within them. In this way, the temperature close to the optic complex and within the third ventricle could eventually be recorded when these structures were manipulated under high magnification. At these moments, the tip of light-delivering telescope was fixed nearby for relatively long time. During some manipulations, e.g. during harvesting of pedicled mucosal septal flap, the thermocouple had to be withdrawn and then reintroduced. It must be mentioned that the temperature was recorded directly onto computer, whereas the surgeon routinely worked being unaware of current temperature level.

Esophageal temperature (Tes) was recorded in all patients as a reference temperature, representing the core body temperature. This was measured with a $1.2 \mathrm{~mm}$ flexible thermocouple introduced through the mouth and placed 32 $36 \mathrm{~cm}$ below the lips [12] Temperature values were read by a TM-12 thermometer (Physitemp, USA) with an accuracy of $0.1^{\circ} \mathrm{C}$, and a resolution $0.01^{\circ} \mathrm{C}$, sampled every $2 \mathrm{~s}$ with a computer- operated data acquisition system and logged on to a disc. The duration of continuous temperature recordings ranged from $69 \mathrm{~min}$ to $143 \mathrm{~min}$ (mean $91 \mathrm{~min}$ ).

\section{Results}

At the beginning of the temperature recording, a mean value of the trunk core temperature (represented by Tes) was $36.0{ }^{\circ} \mathrm{C} \pm 0.45^{\circ} \mathrm{C}$, whilst the mean value of the intranasal temperature close to the operative field (Tof) was $36.8^{\circ} \mathrm{C} \pm$ $0.80{ }^{\circ} \mathrm{C}$; the values averaged for all patients. At the completion of the main phase of the operation (tumor removal), the mean trunk core temperature did not increase and was on average $36.0 \pm 0.48{ }^{\circ} \mathrm{C}$. This was in contrast with the operative field temperature, which instead showed a constant increment in all cases, reaching an average value of $41.0 \pm$ $1.83{ }^{\circ} \mathrm{C}$ at the final stage of the procedure. Therefore, the difference between the temperature of the operative field and the trunk core temperature increased from an initial value of $0.81 \pm 0.84{ }^{\circ} \mathrm{C}$ to $5.02 \pm 2.01{ }^{\circ} \mathrm{C}$. It is of note that in two cases we observed a consistently high intranasal temperature reaching up to $43{ }^{\circ} \mathrm{C}$ and occasionally higher. Moreover, apart from this general trend, momentary excursions of the temperature up to even $62.5^{\circ} \mathrm{C}$ were noted 
during bone drilling or during the application of ultrasonic aspiration (CUSA).

Figure 1 shows an example of temperature recording in a 55-year-old male who was operated on because of a suprasellar adenoma. At the beginning of the procedure, the temperature of the operative field oscillated around Tes, but rapidly increased up to $45^{\circ} \mathrm{C}$ during sphenoid bone drilling with a high-speed diamond burr (asterixes). Sterile lukewarm saline solution was used to irrigate the operative field after each session of bone drilling and this maneuver brought the temperature down to the initial level. We noted that the highest temperature was reached after periods of $8 \mathrm{~s}$ of bone drilling. Continuous drilling for $12 \mathrm{~s}$ resulted in a sudden unusually high temperature peak of $62{ }^{\circ} \mathrm{C}$ (double asterix). Very gentle drilling of the planum sphenoidale was associated with an increase in temperature up to $43{ }^{\circ} \mathrm{C}$ within 3 min (arrow).

In the second phase of the operation (marked on the graph with a shadow), both the thermocouple and the optic were advanced behind the dura and the content of the tumor was evacuated with a ring curette under high magnification and with endoscope fixed manually in a close proximity to the operated intradural structures. During this phase of the surgery, the temperature in the illuminated intradural structures remained $42-43{ }^{\circ} \mathrm{C}$ with an increasing trend. During this step, the temperature decreased during the flushing/aspiration of the operative field and/or due to inadvertent temporal displacement of the thermocouple out of the intradural space.

The temperature trend was obtained by approximation of the series with distance-weighted least square smoothing technique (DWLS) and tension parameter set at 0 . In order to avoid inclusion of the temperature when the probe was

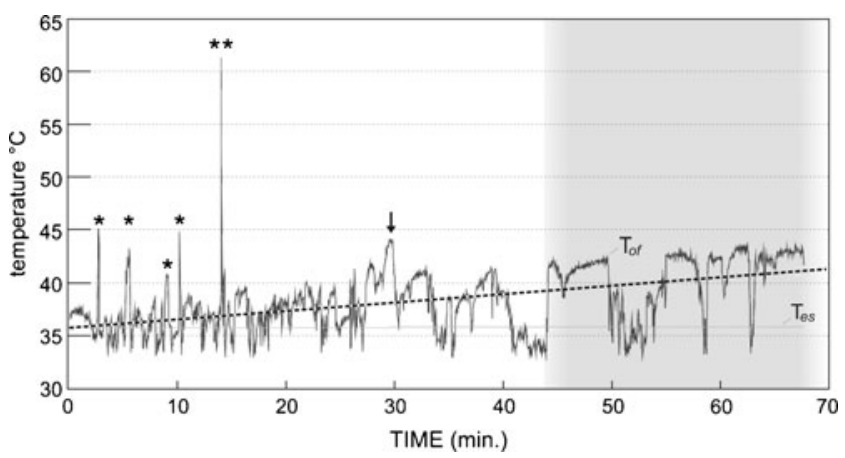

Fig. 1 Temperature of the operating field (Tof) and trunk core temperature (represented by esophageal temperature-Tes) during endoscopic removal of suprasellar adenoma. Asterix marks temperature peaks of $43-45{ }^{\circ} \mathrm{C}$ associated with each $8 \mathrm{~s}$ session of bone drilling within sphenoid sinus. Double asterix marks temperature peak of $60^{\circ} \mathrm{C}$ associated with $12 \mathrm{~s}$ of bone drilling and arrow marks a 3 min period of intermitted but gentle drilling of planum sphenoidale. During intradural phase of procedure (shadowed part of graph), thermoprobe advanced intrasellary indicated local temperature of $43^{\circ} \mathrm{C}$. Dashed line indicates increasing trend of temperature during the entire period of measurement out, the trend was calculated only from the values of temperature exceeding the core trunk temperature. The obtained line of trend demonstrates a continuous increment of the temperature within the operative field during the whole procedure, with an average rate of growth of $0.08{ }^{\circ} \mathrm{C} / \mathrm{min}$, which corresponds to a rate of $\sim 5^{\circ} \mathrm{C}$ per hour.

Figure 2 shows the changes of the intranasal temperature in a patient operated for a sarcoma infiltrating the sphenoid and cavernous sinus and the clivus. The shadowed part of the plot indicates tumor debulking with CUSA. Even during the initial phase of preparation (in which no CUSA and no drilling were used), the operating field temperature increased gradually from $37.5{ }^{\circ} \mathrm{C}$ (i.e. a level corresponding to the deep trunk temperature) to values exceeding $40{ }^{\circ} \mathrm{C}$. When the CUSA was used continuously for $10 \mathrm{~min}$ during the removal of the intraclival part of the tumor, a steady increase of the local temperature up to the value of $45^{\circ} \mathrm{C}$ was observed (arrow), in spite of parallel use of surgical aspiration. During piecemeal removal of the tumor, achieved with intermittent use of the CUSA (see last 20 min on the graph), the thermocouple was exposed to direct illumination from a short distance and temperature increased up to $50{ }^{\circ} \mathrm{C}$. The line of trend shows a continuous increment up and above $43{ }^{\circ} \mathrm{C}$, with an estimated average rate of increment of $3.6^{\circ} \mathrm{C} / \mathrm{h}\left(0.06{ }^{\circ} \mathrm{C} / \mathrm{min}\right)$.

Short samples of temperature records in three different patients are aggregated in Fig. 3, in order to depict time dynamics of temperature excursions during certain surgical maneuvers. Figure 3 a shows temperature course during bone drilling over the paraclival segment of the carotid artery in a patient with petrous apex cholesterol granuloma. The thermocouple was placed in close vicinity to the site of drilling. Each period of bone drilling was associated with an immediate rise of the temperature from the baseline value $\left(36{ }^{\circ} \mathrm{C}\right.$ ) up to $40-44{ }^{\circ} \mathrm{C}$, and in some instances even up to $50-51{ }^{\circ} \mathrm{C}$.

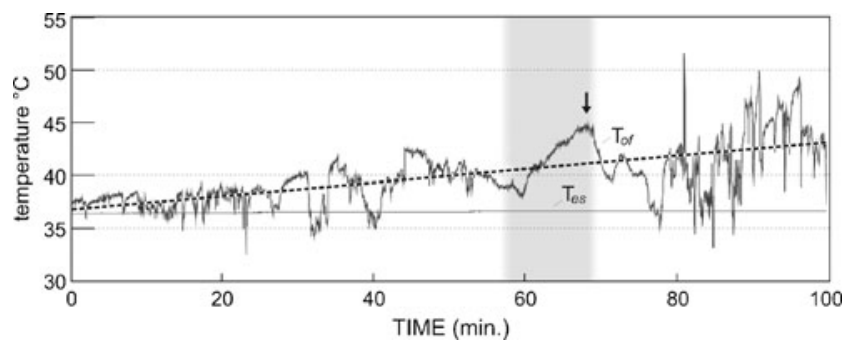

Fig. 2 Temperature of the operating field (Tof) and trunk core temperature (Tes) during endoscopic removal of sarcoma infiltrating the sphenoid and cavernous sinuses and the clivus. Dashed line: an increasing trend of operative field temperature during procedure. Continuous use of ultrasonic aspiration for $10 \mathrm{~min}$ (shadow) is associated with temperature increase up to $45^{\circ} \mathrm{C}$. Intermittent use of CUSA under direct illumination of the thermocouple from close distance increases local temperature up to $50{ }^{\circ} \mathrm{C}$ (last $20 \mathrm{~min}$ of procedure) 

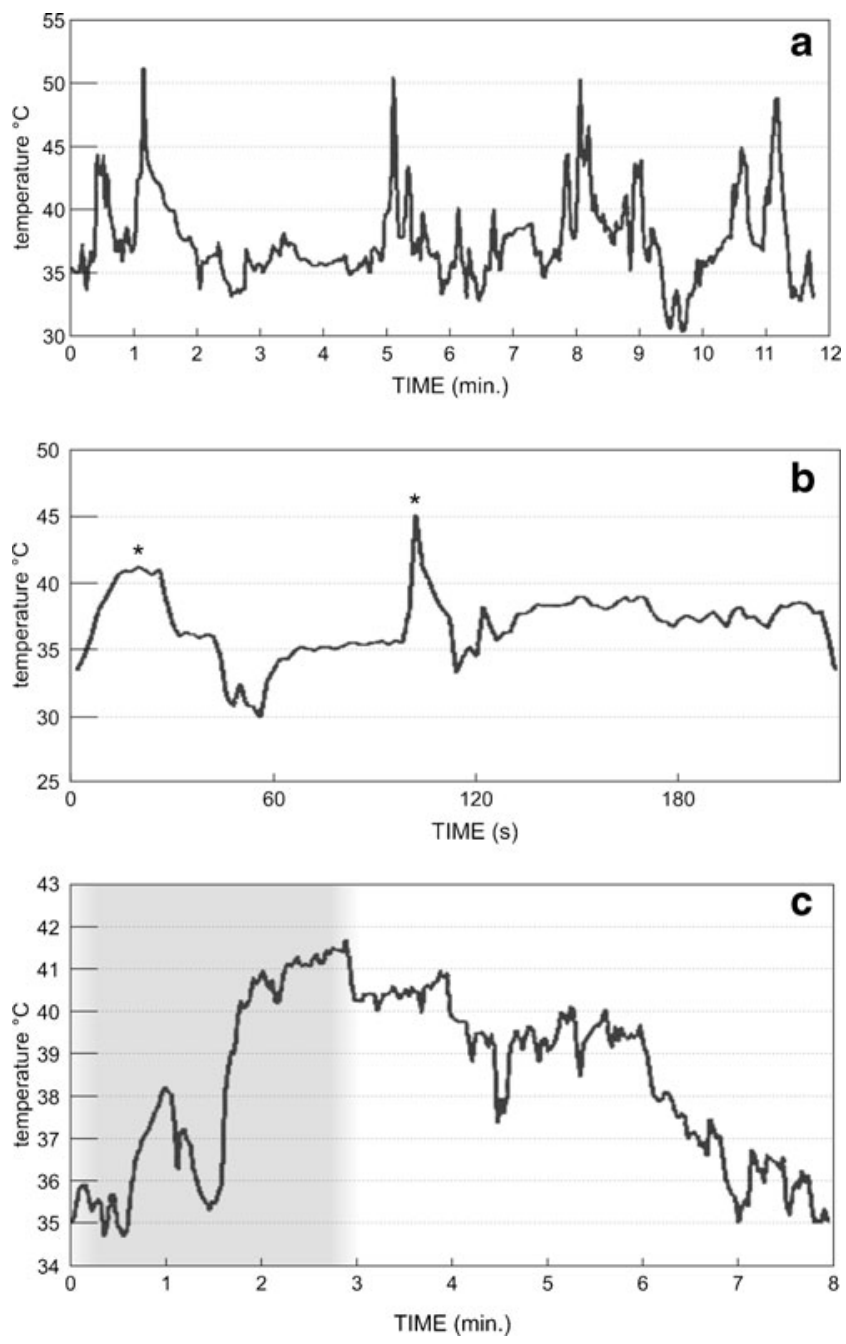

Fig. 3 Short samples of temperature records in three different patients. a temperature of the operative field in patient with petrous apex cholesterol granuloma. There was an immediate rise of temperature from baseline value of $36{ }^{\circ} \mathrm{C}$ up to $50-51{ }^{\circ} \mathrm{C}$ during bone drilling. b thermoprobe inserted epidurally through small perforation in the sellar floor in patients with macroadenoma. Intrasellar temperature rises up to 41 and $45^{\circ} \mathrm{C}$ during thinning of the sellar floor with a high-speed drill (asterix). c cauterization of vascularized tumor within the sphenoid sinus (2.5 min, shadow area). Temperature of the operative field increases up to $41.5^{\circ} \mathrm{C}$, but its return to initial level takes $5 \mathrm{~min}$

Figure $3 \mathrm{~b}$ shows the temperature during bone drilling in a patient with a macroadenoma. In this patient, the thermocouple was introduced through a small perforation of the sella behind the bone of the sellar floor, epidurally. The standard approach aims to drill the sellar floor, thinning it in an "egg shell" manner to enable its removal with a rongeur. Within few seconds, this maneuver yielded an intrasellar increase of temperature up to 41 and $45^{\circ} \mathrm{C}$ during a second attempt.

Figure $3 \mathrm{c}$ demonstrates a section of the temperature record in the same patient as in Fig. 2. Extended time scale demonstrates the temperature course during a $3 \mathrm{~min}$. session of intensive, though intermittent cauterization of a highly vascularized tumor within the sphenoid sinus (shadow area). During this phase, the temperature increased from $35.5{ }^{\circ} \mathrm{C}$ to almost $42{ }^{\circ} \mathrm{C}$ and the return to the initial level took as long as $5 \mathrm{~min}$.

\section{Discussion}

Thanks to unrelenting efforts of several advanced teams, it has been demonstrated that virtually the entire ventral cranial base is accessible with endoscopic technique, and many sophisticated procedures have became feasible in the past decade $[1-3,8,9]$. Nevertheless, it is mandatory that feasibility, granted by continuous evolution of the technical instruments, is coupled with safety and efficiency, whilst at the same time the technique itself has to be standardized. Transnasal endoscopic skull base surgery is seldom described as a "minimally invasive" technique, but it is not, and several aspects of its safety have yet to be outlined and be studied. Thermal effect on the brain and the surrounding structures is one of them, but to date has not been explored in large series nor highlighted as potentially harmful.

Our study, although on a small series of patients, demonstrates that during prolonged transnasal endoscopic approaches to the skull base the temperature within the operative field increases steadily to eventually reach and exceed in some patients $42{ }^{\circ} \mathrm{C}$. This heating effect is expected to happen in virtually all patients in spite of suctioning and flushing of the operative field with lukewarm saline solution. Furthermore, high-speed drilling of the bone is associated with transient increments of the local temperature up to $50-60{ }^{\circ} \mathrm{C}$, whereas during a $10 \mathrm{~min}$ long use of the CUSA, temperature can increase up to $45{ }^{\circ} \mathrm{C}$. These changes in the operative field temperature were all observed in patients whose core trunk temperature remained at a mildly hypothermic level of 35$36^{\circ} \mathrm{C}$, commonly seen during general anesthesia [13].

Such high temperature of the operative field within the skull base is likely to jeopardize cerebral structures, especially during the intracranial phase of operation. It is well known that human brain, even under normal conditions, is exceptionally susceptible for temperature. Rectal temperature of $41.9^{\circ} \mathrm{C}$ has been recorded at the end of marathon run and of $42.5^{\circ} \mathrm{C}$ in collapsed runners $[5,6]$. Most authors agree that adverse metabolic effects appear in the brain at the temperature of $40.5-41{ }^{\circ} \mathrm{C}$ and brain temperature $41.5-42{ }^{\circ} \mathrm{C}$ is potentially lethal [5]. Therefore, the "safe zone" for temperature increase of the brain is very narrow. It must also be remembered that cerebral structures of interest can be compressed by a mass lesion with resultant local ischemia, and it is well known that ischemic brain is particularly sensitive for small $\left(1-3{ }^{\circ} \mathrm{C}\right)$ increases in temperature [14].

It is also worth of remembering that the nasal cavity, when normally ventilated, is a potent heat sink for the brain, thanks to venous corridors that connect these two cranial 
compartments and can transfer cooled blood from the nasal mucosa to the basal aspects of the brain $[15,16]$. In particular, it has been shown that in intubated mildly hyperthermic patients the temperature of basal aspect of the brain is the highest core body temperature, and it falls even below the trunk core temperature immediately after extubation and reintroduction of the normal ventilation through the nose [11]. Obviously, during the endonasal endoscopic procedures the nasal cavity is by-passed by an endotracheal tube and cannot be cooled by the inspired air. All these circumstances create a potentially danger situation in which cerebral structures exposed to the "dead space" of nasal cavity are not only disabled of dissipation of their normal metabolic heat, but are also subject to uncontrolled increases of temperature, due to intense illumination and surgical manipulations.

When looking into the causes of this adverse temperature increase, the telescope itself ought to be considered as a potent source of heat transmitted with seemingly "cold" light. Endoscopic practitioners know that an endoscope left on the operative table with its tip at surgical scrub can burn this material. According to other data, the temperature of the tip of a telescope may reach even $200{ }^{\circ} \mathrm{C}[7,8,17]$. ENT surgeons have already signaled the problem of temperature, indicating that heat generated on the tip of the endoscope can harm intranasal structures $[7,8,17]$. Nevertheless, this problem has never been addressed in relation to skull base surgery through extended endoscopic approaches.

These procedures are much more extensive than "typical" pituitary surgery, which is longer and performed with the telescope fixed for a long time in a close distance to operated structures. Wide exposure creates a large cavity in which the telescope can be freely manipulated with no need of frequent cleaning with saline. The anatomical mucosal structures are either resected, pushed aside or harvested for closure thus depriving the nose of the convectional heat clearance. Our temperature records illustrate that the temperature of the operative field in such instances increases incessantly and reaches a potentially dangerous level of $42{ }^{\circ} \mathrm{C}$ and more. Such temperature elevation can be potentially tolerable when confined to the nasal cavity, paranasal sinuses or clivus, though its real direct biological effects and delayed consequences are not known and need further studies. Specifically, the rate of such complications like infections, CSF leaks or dysfunctions of neighboring neural structures can potentially be influenced by thermal stress/injury.

Obviously, a real danger appears when temperature increases to the level above $42^{\circ} \mathrm{C}$ within the intradural space. This happens when the telescope is fixed at a close distance to the intradural structures to obtain high magnification. In our patients, temperature at this stage of the operation increased incidentally even up to $43.6^{\circ} \mathrm{C}$ and a mean temperature of the operative field in three patients during the intradural phase of operation was $41.7^{\circ} \mathrm{C}$.
Besides heat transmission from the telescope, bone drilling, ultrasonic aspiration and cauterization must also be considered as potential heat sources contributing to increase of the temperature. Especially bone drilling was demonstrated to increase the local temperature even to the level of 50 $60{ }^{\circ} \mathrm{C}$ within seconds. This can be due to a fact that bone drilling in a closed space and under endoscopic visualization cannot be carried out with any extensive irrigation, because splashing bone dust soaked with water would get the tip of the scope messy. For this reason, bone drilling (in a contrast to microscopic operations), is usually performed in a dry field, irrigated only when the drill stops.

The aim of this study was to examine changes of temperature of the operative field during routine endoscopic procedures while the surgeon was not aware of current temperature level. This is why both suctioning and flushing of the field with the saline solution were used with no intention of temperature reduction, but rather to clear the vision. Normally the surgeon tends to keep the operative field as dry as possible because this enables fast progression of the procedure. Also, in our set-up flushing with saline was used moderately, usually after each session of bone drilling or cauterization. It can also be added that the Clear Vision system set (Karl Storz Endoscope) that is dedicated for cranial base surgery, flushes only the tip of the endoscope and not the operative field. As a matter of fact, such sudden and unexpectedly high increases of temperature associated with surgical manipulation under endoscope came as an surprising finding. The only remedy we can propose is to perform drilling, cauterization and ultrasound aspiration in short, few second sessions with associated suction. The exact site of bone drilling ought to be changed for each drilling session, and the field must be spilled with saline more often than is needed for maintenance of clear vision.

\section{Limitations of the study}

Measurement of the temperature of the operative field deep in the nasal cavity was a demanding task. We tried to place a thermocouple and keep it close to the site of surgical manipulation, which was not always possible because the probe often slipped out and was pushed away by working instruments. For this reason, the temperature records obtained are not smooth and in many moments, the recorded temperature turned out to be even lower than the trunk core temperature. Nevertheless, what really matters are the highest recorded temperatures, as they can endanger the operated structures. What is important, the temperature in many moments or periods was much higher than one could have expected. Moreover, it must be also noted that the tip of the thermocouple relied rather on a certain distance from the exact site of surgical action like bone drilling or cauterization, and therefore the temperature in these critical places was likely to be even higher. 


\section{Conclusion}

Endoscopic skull base surgery is associated with an incessant increase of the temperature of the operated structures. Additionally, the temperature can peak suddenly to levels that can harm neighboring biological structures and possibly influence the rate of postoperative complications.

\section{Conflicts of interest None.}

Open Access This article is distributed under the terms of the Creative Commons Attribution License which permits any use, distribution, and reproduction in any medium, provided the original author(s) and the source are credited.

\section{References}

1. Kassam AB, Prevedello DM, Carrau RL, Snyderman CH, Thomas A, Gardner P, Zanation A, Duz B, Stefko ST, Byers K, Horowitz MB (2011) Endoscopic endonasal skull base surgery: analysis of complications in the authors' initial 800 patients. J Neurosurg 114:1544-1568

2. Lyson T, Sieskiewicz A, Rutkowski R, Kochanowicz J, Turek G, Rogowski M, Mariak Z (2013) Transnasal endoscopic approaches to the cranial base. Neurol Neurochir Pol 47:63-73

3. Prevedello DM, Kassam AB, Snyderman C, Carrau RL, Mintz AH, Thomas A, Gardner P, Horowitz M (2007) Endoscopic cranial base surgery: ready for prime time? Clin Neurosurg $54: 48-57$

4. Sieskiewicz A, Lyson T, Mariak Z, Rogowski M (2008) Endoscopic trans-nasal approach for biopsy of orbital tumours using image-guided neuro-navigation system. Acta Neurochir 150:441-445

5. Cabanac M (1993) Selective brain cooling in humans: "fancy" or fact? FASEB J 7:1143-1146

6. Hales JR, Stephens FR, Fawcett AA, Westerman RA, Vaughan JD, Richards DA, Richards CR (1986) Lowered skin blood flow and erythrocyte sphering in collapsed fun-runners. Lancet 28:1495-1496

7. MacKeith SA, Frampton S, Pothier DD (2008) Thermal properties of operative endoscopes used in otorhinolaryngology. J Laryngol Otol 122:711-714

8. McMullin BT, Blumin JH, Merati AL (2007) Thermal injury to the tongue from an operative laryngoscope. Otolaryngol Head Neck Surg 137:798-802

9. Sieskiewicz A, Lyson T, Rogowski M, Rutkowski R, Mariak Z (2011) Endoscopic repair of CSF leaks in the postero-superior wall of the frontal sinus - report of 2 cases. Minim Invasive Neurosurg $54: 260-263$
10. Mariak Z, Jadeszko M, Lewko J, Lebkowski W, Lyson T (1998) No specific brain protection against thermal stress in fever. Acta Neurochir 140:585-590

11. Mariak Z, White MD, Lewko J, Lyson T, Piekarski P (1999) Direct cooling of the human brain by heat loss from the upper respiratory tract. J Appl Physiol 87:1609-1613

12. Dietrich WD, Busto R, Halley M, Valdes I (1990) The importance of brain temperature in alterations of the blood - brain barrier following cerebral ischemia. J Neuropat Exp Neurol 49:486-497

13. Mariak Z, Lebkowski W, Lyson T, Lewko J, Piekarski P (1999) Brain temperature during craniotomy in general anesthesia. Neurol Neurochir Pol 33:1325-1337

14. Busto R, Dietrich WD, Globus MY, Valdés I, Scheinberg P, Ginsberg MD (1987) Small differences in intraischemic brain temperature critically determine the extent of ischemic neuronal injury. J Cereb Blood Flow Metab 7:729-738

15. Rasch W, Cabanac M (1993) Selective brain cooling is affected by wearing headgear during exercise. J Appl Physiol 74:1229-1233

16. White MD, Cabanac M (1995) Nasal mucosal vasodilatation in response to passive hyperthermia in humans. Eur J Appl Physiol Occup Physiol 70:207-212

17. Nelson JJ, Goyal P (2011) Temperature variations of nasal endoscopes. Laryngoscope 121:273-278

\section{Comment}

The authors have performed an important study. They have measured the temperature of the operative field while performing endonasal endoscopic surgery for a variety of tumors. They note a steady increase in temperature during the procedure in all cases, with dangerously high spikes of temperature while using the drill and ultrasonic aspirator. This reviewer found this to be very informative, and it reminds all of us that the light emanating from the endoscope, the use of the high-speed drill, and the ultrasonic aspirator generate significant heat which cannot dissipate in this closed space. This is especially critical for heat exposure of the perforating basal arteries, and the optic chiasm, which are the most sensitive structures in the surgical region exposed during an endoscopic approach. This study should prompt these authors and others to refine the analysis of heat generation and develop techniques and protocols with irrigant quantity and temperature to mitigate against this dangerous temperature rise.

I have seen cases of unilateral visual deficit in patients following endoscopic approaches in which manipulation of the nerve was minimal; heat exposure to the nerve or its nutrient perforator supply provides a possible mechanism for this complication. The authors are to be commended for this important study, which educates us to a potential hazard with the technique.

WT Couldwell

Utah, USA 